\title{
Comparative Analysis of an Off-grid PV System for Different Types of Batteries
}

Case Study

\author{
Rebeka Raff \\ Josip Juraj Strossmayer University of Osijek, \\ Faculty of Electrical Engineering, Computer Science and Information Technology Osijek, Croatia \\ raff.rebeka@gmail.com
}

\author{
Velimir Golub \\ Josip Juraj Strossmayer University of Osijek, \\ Vodovod-Osijek d.o.o. \\ velimir.golub@vodovod.com
}

\section{Jurica Perko}

Regional Energy Agency North

jurica.perko@rea-sjever.hr

\begin{abstract}
The aim of this paper is to find an optimal size of different components of an off-grid PV system in the HOMER software with different types of batteries (lead-acid batteries and lithium-ion batteries). The proposed model shows the optimal size of the off-grid PV system for a holiday cottage with regard to eligibility criteria for various types of batteries and the net present cost (NPC). The observed offgrid PV system consists of PV modules, a load, a converter and batteries and it is modelled in the HOMER software. The load is modelled with a daily load diagram for the holiday cottage. For lead-acid and lithium-ion batteries the optimal size of different components of an off-grid PV system for five different scenarios (in respect of the price and life-time) is obtained. In addition, the optimal size of the presented model with respect to different values of capacity shortage ranging from $0 \%$ to $5 \%$ is presented.
\end{abstract}

Keywords - HOMER, lead-acid battery, lithium-ion battery, off-grid PV system, optimization

\section{INTRODUCTION}

In the past few years, due to many various factors such as global warming, energy security, constant improvements in technology and decreasing prices, the PV sector is rapidly expanding. According to the IEA, 2016 was characterized by an enormous growth of the PV market and the global PV market installed almost $76 \mathrm{GW}$ of capacity worldwide, so cumulative installed capacity by solar installations reached almost $303 \mathrm{GW}$ by the end of year 2016 [1]. This installed capacity is related to grid-connected PV systems.

PV technology has versatility and flexibility for developing off-grid electricity systems and it is ideal for the areas where grid connections are not accessible, such as remote areas, holiday cottages, etc. According to [2], PV systems have become standard in areas where there is no access to the electricity network (cottages, etc.). This type of a stand-alone PV system consists of PV modules, a load, a converter and batteries, but it also entails a fossil fuel generator connected for backup purposes.
The overall goal of designing an off-grid PV system is the estimation of consumption and solar potential. During solar system design, one of the main factors is solar radiation data at specific locations [3]. According to [4], there is always a challenge for the researcher to improve the performance of the solar PV system to achieve maximum solar radiation. According to [5], to make PV systems maximally efficient, it is important to consider all the influencing factors when designing a system. After identifying the needs of the user and solar potential, it is important to provide maximum efficiency, flexibility and reliability with optimum costs of system application. To achieve this goal, it is most crucial to have stable energy access so the installation of energy storage units is required. While designing an optimal off-grid PV system, the crucial first point is to consider battery sizing, given that it is one of the main cost components in typical off-grid PV-based residential energy systems [6]. However, in the past few years, due to constant improvements in solar technologies, the prices of all PV components have declined, which has led to the lower initial cost of solar batteries. In or- 
der to provide cost analysis of an off-grid PV system, the total cost of the system needs to be calculated and all the expenses to incur over the life of the system expressed in today's money needs to be included [7]. For residential applications, according to [8], the actual prices for battery storage units range between 100 and $250 € / \mathrm{kWh}$ for lead-acid batteries (LAB), and between 200 and $750 € /$ kWh for lithium- ion batteries (LIB).

Considering the important role energy storage systems have in the feasibility of the complete PV model design, in the last decade particular attention was paid to the development of a safer storage solution regarding battery management [9]. Comparison of off-grid power supply systems using lead-acid and lithium-ion batteries is presented in several research papers [1012]. By late 2015, several manufacturers such as Tesla Motors, NEC and Panasonic, introduced their improvements in energy storage devices to the PV sector [13].

A true advancement in storage technology can be seen in lithium-ion batteries that have almost replaced widely used lead-acid batteries. Although they are more advanced and revolutionary, lithium-ion batteries have not entirely replaced lead-acid batteries. It can be assumed that the main reason for choosing lead-acid batteries instead of lithium-ion ones is their substantially lower initial investment. Current market prices show that the initial cost for lithium-ion batteries can be up to six times higher than for lead-acid batteries, which in many cases may act as a deterrent to purchasing this type of battery [14]. If the price is excluded, the domination of lithium-ion batteries is indisputable. When comparing these two types of batteries, it is evident that it is a one-way street, because for the same duration, lead-acid batteries can only be discharged to half of their capacity, while lithium-ion batteries can be discharged up to $80 \%$ of their capacity, and in that case they will not be damaged [15]. If both types of batteries were connected to the same load and required to supply the load in the same amount of time, the leadacid battery should be twice as large in terms of capacity and four times as heavy [14]. However, in the end, investors will decide which type of battery is more acceptable for them.

The purpose of this paper is to present the optimal size of different components of an off-grid PV system in the HOMER software as well as different types of batteries. The proposed model will show the optimal size of the obtained off-grid PV system for the holiday cottage with regard to eligibility criteria for various types of batteries and the net present cost (NPC).

\section{INTRODUCTION}

An off-grid PV system for a holiday cottage that does not have access to a grid but needs an alternative power source is discussed in this paper. This simplified PV model consists of basic components: PV modules, a converter, batteries and an electrical load (Fig. 1.)

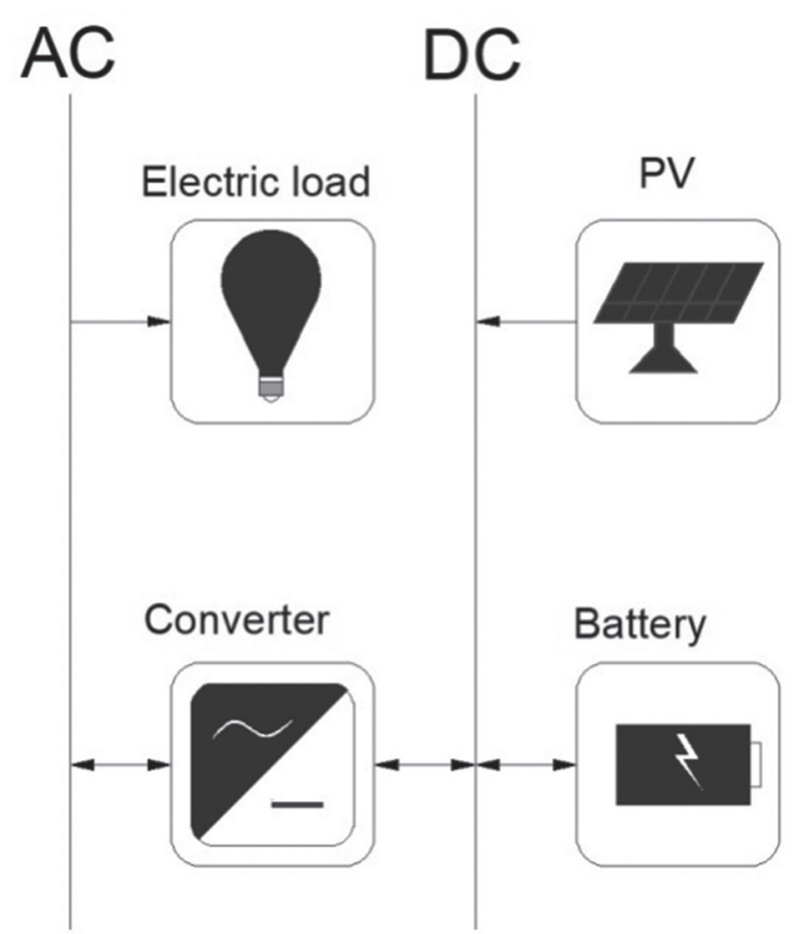

Fig. 1. A simplified off-grid PV model

The observed off-grid PV model will be tested with respect to different types of batteries and optimized in the HOMER software. In this paper, an advanced HOMER algorithm called the HOMER Optimizer will be used. To start the optimization of an off-grid PV system in the HOMER Optimizer, it is sufficient to enter the following data: electrical load values, purchase costs of all PV components and the amount of sun radiation reaching the Earth's surface on a horizontal surface for the observed location. According to those parameters, the HOMER Optimizer finds the least-cost combination of all components, also as the optimum size and power thereof to meet the electrical load. The HOMER Optimizer will provide the most economically viable options regarding all PV components and classify those options regarding the net present cost [16].

For this purpose, two types of batteries will be used, i.e. a lead-acid battery and a lithium-ion battery. The initial intent was to use the third type of battery - VRB; however, HOMER does not support all necessary data pertaining to this type of battery. This model will be based on fixed $2 \%$ O\&M costs of the complete system. Table 1 presents the main characteristics and differences of those two types of batteries. The characteristics were taken from the HOMER software, specifically the characteristics for a generic lead-acid $1 \mathrm{kWh}$ battery and a generic lithium-ion $1 \mathrm{kWh}$ battery.

The battery price range is defined according to [8] for both types of batteries and, as can be seen in Table 2 , the purchase cost can vary. However, in the model obtained for the optimization only limited values (the lowest and the highest price) of battery prices will be used for both types of batteries. Apparently, the price of a lithium-ion battery will be more than three times 
higher than the price of a lead-acid battery. This implies that the investment in an off-grid PV system with a lead-acid battery will cost less than the investment in a PV system with a lithium-ion battery. In this paper, we will try to find out whether lithium-ion batteries are beneficial in the long run.

Table 1. Comparison of a lead-acid $1 \mathrm{kWh}$ and a lithium- ion $1 \mathrm{kWh}$ battery

\begin{tabular}{|ccc|}
\hline Modified kinetic battery model & $\begin{array}{c}\text { Lead-acid 1 } \\
\text { kWh }\end{array}$ & $\begin{array}{c}\text { Li-ion 1 } \\
\text { kWh }\end{array}$ \\
\hline Nominal Voltage (V) & 2 & 3.7 \\
\hline Nominal Capacity (kWh) & 1.03 & 1.02 \\
\hline Maximum Capacity (Ah) & 513 & 276 \\
\hline Capacity Ratio & 0.611 & 1 \\
\hline Rate Constant (1/hr) & 1.09 & 1 \\
\hline Effective Series Resistance (ohms) & 0.000596 & 0.00036 \\
\hline Other round-trip losses (\%) & 15 & 8 \\
\hline Fixed bulk temperature (C) & 20 & 20 \\
\hline Maximum Operating Temperature (C) & 55 & 60 \\
\hline Minimum Operating Temperature (C) & -20 & 0 \\
\hline Maximum Charge Current (A) & 167 & 270 \\
\hline Maximum Discharge Current (A) & 500 & 810 \\
\hline
\end{tabular}

The purchase cost of PV panels and converters is considered according to [17] and in the model obtained for the optimization problem the average price of the purchase cost for PV panels and converters will be used. The purchase cost for PV panels is based on the average market price of different PV panel producers with equivalent characteristics as well as the purchase cost for converters based on the average market price of different converter producers with equivalent characteristics.

Table 2 presents the prices of all PV components that will be used in the obtained model.

Table 2. PV component prices

\begin{tabular}{|ccc|}
\hline Component & $\boldsymbol{\epsilon} / \mathbf{k W}$ & $\boldsymbol{\epsilon} / \mathbf{k W h}$ \\
\hline PV Panel & $613-1300$ & - \\
\hline Battery Lead-Acid & - & $100-250$ \\
\hline Battery Li-lon & - & $200-750$ \\
\hline Converter & $111-590$ & - \\
\hline
\end{tabular}

According to [8], when battery lifetime of those two types is considered, lead-acid batteries typically operate for 5 to 15 years, while lithium-ion batteries can operate for 7 to 20 years. To find an optimal size of different components of the observed system, it is necessary to define the project lifetime. Given the typical lifetime of PV panels that is estimated at 20 years, the investment period is also set for the 20 years period for the purposes of this model [7].

The first step in modeling an off-grid PV system is to define an electrical load for the proposed holiday cottage. To determine the load diagram for model optimization, the data provided, pertaining to an electrical load, were measured in a house in Osijek. Measurements were conducted every 10 minutes during 24 hours for a period of 7 days. The average value of all samples taken every 10 minutes per hour was calculated by means of the HOMER software, which allows the user to enter data regarding the average hourly load. In this test, hourly values of 10 minutes are obtained and to provide one year of hourly load data it is assumed that a 7-day diagram is the same for each week throughout the whole year. An electrical load table for the observed model is presented in Figure 2.

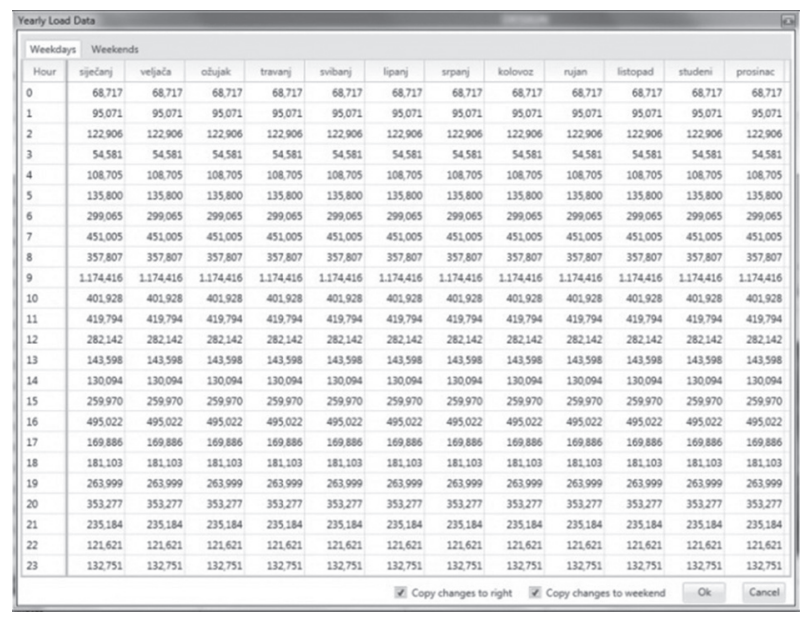

Fig. 2. Electrical load table from HOMER

The electrical load diagram is presented in two different sections: a weekday load diagram shown in Figure 2 and a weekend day load diagram shown in Figure 3.

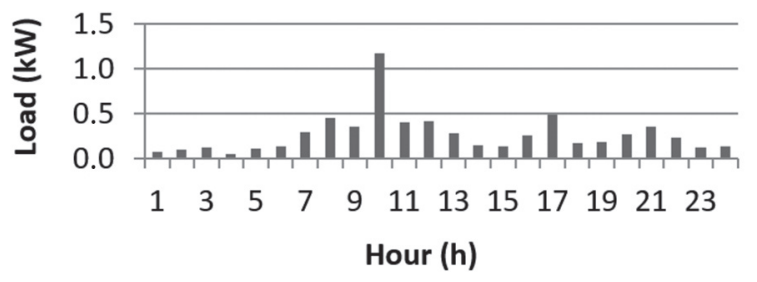

Fig. 3. Weekday load diagram

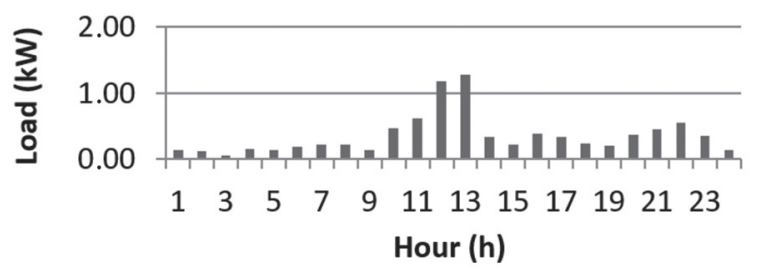

Fig. 4. Weekend day load diagram

The second step in the process of modeling an offgrid PV system is to know the amount of sun radiation reaching the Earth's surface on a horizontal surface for the observed location. This value is called GHI (global horizontal irradiance) and it is of particular interest in 
PV installations. In the case of the PV model presented in this paper, the GHI value is taken from the PV system that provides information from most popular and reliable sources, such as Meteonorm, NASA-SSE, Solar GIS, PVGIS, Helioclim-1 and RETScreen [18] that collect data in monthly values. The optimal size of the observed model is performed according to data for the daily irradiance profile taken from the PVGIS, which are calculated on a 10-year period (2007-2016, including both years) throughout months and the obtained average daily radiation ( $\mathrm{kWh} / \mathrm{m} 2 /$ day) is used in HOMER simulation. A solar radiation database used in the optimal size of the observed model is based on the model algorithm that estimates beam, diffuse and reflected components of the clear-sky and real-sky global irradiance/ irradiation on horizontal or inclined surfaces and the total daily irradiation is computed by the integration of irradiance values calculated at regular time intervals over the day [18].

Besides GHI, for PV production it is also important to define the panel tilt angle. The variation of solar declination can be calculated by means of the following equation [5]:

$$
\delta=23.45 \sin \left(\frac{360}{365}(284+N)\right)
$$

where $\mathrm{N}$ is a day in a year.

$$
\beta_{N}=90^{\circ}-L+\delta
$$

where $\beta_{N}$ is the elevation angle and $L$ is the latitude.

Using equations ( 1 ) and (2), the panel tilt angle is calculated for the location in Osijek. According to previous calculation, the panel tilt angle used in the simulation is $33^{\circ}$, which is the most optimal angle for PV panels for the Osijek location.

Table 3 shows data about GHI based on $\mathrm{kWh} / \mathrm{m} 2 /$ day taken from the PV system used in the HOMER software for the obtained location on a monthly basis.

Table 3. GHI (kWh/m2/day) for the observed location

\begin{tabular}{|cc|}
\hline Months & GHI $(\mathbf{k W h} / \mathbf{m} \mathbf{2} /$ day $)$ \\
\hline January & 1.09 \\
\hline February & 1.89 \\
\hline March & 2.70 \\
\hline April & 3.67 \\
\hline May & 5.02 \\
\hline June & 5.31 \\
\hline July & 5.56 \\
\hline August & 4.92 \\
\hline September & 3.59 \\
\hline October & 2.22 \\
\hline November & 1.24 \\
\hline December & 0.91 \\
\hline
\end{tabular}

\section{CASE STUDY}

In this case study, five scenarios (A, B, C, D, and E) related to the battery price and lifetime of both types of battery (lead- acid and lithium-ion battery) will be examined. Scenario " $A$ " is based on the lowest prices of both types of batteries and their longest lifetime. Scenario " $B$ " is made to the lowest price and the shortest lifetime of both types of batteries. Scenario " $C$ " is designed in respect of the highest price and the shortest battery lifetime for both types of batteries, while Scenario " $\mathrm{D}$ " is based on the highest price and the longest battery lifetime. The last scenario, i.e. scenario " $\mathrm{E}$ ", is made with respect to average battery parameters, i.e. the average battery price and lifetime for both types of batteries.

Simulation results were obtained by means of the HOMER software. The results are based on the aforementioned scenarios derived from changes in the battery parameters. All input parameters regarding the load, PV modules and the converter are the same in all five scenarios, while battery prices and lifetime have changed from case to case.

This system optimization attempts to address two aspects relevant to the observed model. The first aspect is the optimization of system components based on the input data: the electrical load profile for weekdays and weekend days and the GHI. Based on those input data, the HOMER software configures the observed system to be the most optimal taking into consideration the size and quantity as variables. Two key steps in modeling an off-grid PV system are previously described in Section 2.

Before displaying the results, it is necessary to provide explanations to the following terminology that will allow the reader to interpret them.

Storage bank autonomy (Autonomy) is the ratio of the storage bank size to the electric load which HOMER calculates by using the following equation [19]:

$$
A_{\text {batt }}=\frac{N_{\text {batt }} V_{\text {nom }} Q_{\text {nom }}\left(1-\frac{q_{\min }}{100}\right)(24 \mathrm{~h} / \mathrm{d})}{\mathrm{L}_{\text {prim,ave }}(1000 \mathrm{Wh} / \mathrm{kWh})}
$$

Storage throughput (Throughput) is the amount of energy that cycles through the storage bank in one year. Throughput is defined as the change in the energy levels of the storage bank, measured after charging losses and before discharging losses and this value is used to calculate the life of the storage bank [19].

The second aspect relevant to the observed model is from the point of view of cost analysis. Cost analysis for the observed model is based on the purchase cost for all system components. Purchase costs of $x$ and $x$ are the same in all scenarios just like in the case of the project lifetime. However, purchase costs and battery lifetime have changed from case to case. Two batteryrelated variables are most important in model optimi- 
zation and their variation has a greater impact on the following terms:

The net present cost (NPC or the life-cycle cost) is the present value of all costs of installing and operating all components over the project lifetime minus the present value of all revenues it earns over the project lifetime that can be calculated for each component in the system or for the system as a whole [19].

Operating cost is the annualized value of all costs and revenues other than the initial capital costs. HOMER uses the following equation to calculate the operating cost [19]:

$$
C_{\text {operating }}=C_{a n n, t o t}-C_{a n n, c a p},
$$

where:

$C_{a n n, t o t}=$ the total annualized cost $[\$ / y r]$,

$\mathrm{C}_{\mathrm{ann}, \mathrm{cap}}=$ the total annualized capital cost $[\mathbf{S} / \mathrm{yr}]$.

The initial capital cost (IC) of a component is the total installed cost of that component at the beginning of the project.

For a battery as a component in a PV system, it is necessary to explain the following term: SOC (the state of charge) is the total amount of energy currently contained in the storage bank, measured in kWh [19]. SOC used for constraints in the optimization problem is defined in advance and taken from the HOMER software so the initial SOC (the maximum capacity of the battery bank or when the batteries are fully charged) is $100 \%$ and the minimum SOC (the relative state of charge below which the battery bank is never drawn) is $20 \%$.

\subsection{SCENARIO "A" RESULTS}

Simulation in scenario " $\mathrm{A}$ " is based on the lowest price of batteries (100 €/kWh for a lead-acid battery and 200 $€ /$ kWh for a lithium-ion battery) and the longest battery lifetime (15 years for a lead-acid battery and 20 years for a lithium-ion battery) that is the most ideal case from the investor point of view. As this system optimization is observed depending on two different types of batteries and the 20 years project lifetime, the crucial issue for the investor is the final cost of investment.

Table 4 shows scenario " $A$ " results obtained in the HOMER software. In scenario " $A$ ", when installing lithium-ion batteries, the initial cost is $2,799 €$ higher than the initial cost in the case of lead-acid batteries, but in the end the investment will be more profitable in the case of installing lithium-ion batteries because of their replacement, as lithium-ion batteries will not be needed to be replaced during the project lifetime. Leadacid batteries will be needed to be replaced 15 years later and their replacement cost will amount to 8,600 $€$, which is a 5,801 $€$ higher investment, without taking into account $\mathrm{O} \& \mathrm{M}$ costs.
Table 4. Scenario "A" results

\begin{tabular}{cccccc|} 
Case & $\begin{array}{c}\text { PV } \\
(\mathbf{k W})\end{array}$ & $\begin{array}{c}\text { Converter } \\
\mathbf{( k W )}\end{array}$ & $\mathbf{k W h}$ & $\begin{array}{c}\text { Buttery } \\
\text { Autonomy } \\
\mathbf{( h r s )}\end{array}$ & $\begin{array}{c}\text { Annual } \\
\text { Throughput } \\
\text { (kWh) }\end{array}$ \\
\hline LAB & 10.2 & 3.34 & 86 & 111 & 1.935 \\
LIB & 10.4 & 4.11 & 55 & 94.9 & 1.821 \\
\hline Case & $\begin{array}{c}\text { NPC } \\
(\boldsymbol{\epsilon})\end{array}$ & IC (€) & Operating (€) & $\begin{array}{c}\text { Battery } \\
\text { replacement } \\
\text { cost (€) }\end{array}$ \\
\hline LAB & 20,840 & 19,016 & & 159.00 & 8,600 \\
LIB & 21,838 & 21,815 & 2.00 & 0.00
\end{tabular}

\subsection{SCENARIO“B" RESULTS}

Scenario " $B$ " simulation is based on the lowest price of batteries ( $100 € / \mathrm{kWh}$ for a lead-acid battery and 200 $€ / \mathrm{kWh}$ for a lithium-ion battery) and the shortest battery lifetime ( 5 years for a lead-acid battery and 7 years for a lithium-ion battery), which represents the most adverse case from an investor point of view. Table 5 shows scenario " $B$ " results obtained by the HOMER software. In this scenario, the initial cost is $2,138 €$ higher in the case of installing lithium-ion batteries instead of lead-acid batteries. As the project lifetime is 20 years, the costs in the case of installing lead-acid batteries would increase to $41,396 €$ or to $42,234 €$ in the case of installing lithium-ion batteries. It can be concluded that in this scenario the final cost will be higher in the case of installing lithium-ion batteries.

Table 5. Scenario " $B$ " results

\begin{tabular}{ccccccc|} 
Case & $\begin{array}{c}\text { PV } \\
(\mathbf{k W})\end{array}$ & $\begin{array}{c}\text { Converter } \\
(\mathbf{k W})\end{array}$ & $\mathbf{k W h}$ & $\begin{array}{c}\text { Butonomy } \\
\text { (hrs) }\end{array}$ & $\begin{array}{c}\text { Annual } \\
\text { Throughput } \\
\mathbf{( k W h )}\end{array}$ \\
\hline LAB & 13.1 & 3.25 & 71 & 91.9 & 1.857 \\
\hline LIB & 12.1 & 3.78 & 50 & 86.3 & 1.774 \\
\hline Case & $\begin{array}{c}\text { NPC } \\
(\boldsymbol{\epsilon})\end{array}$ & IC (€) & Operating (€) & $\begin{array}{c}\text { Battery } \\
\text { replacement } \\
\text { cost (€) }\end{array}$ \\
\hline LAB & 32,235 & 20,096 & & 1,069 & 21,300 \\
LIB & 32,885 & 22,234 & & 928.61 & 20,000
\end{tabular}

\subsection{SCENARIO “C" RESULTS}

Scenario " $C$ " simulation is based on the highest price of batteries ( $250 € / \mathrm{kWh}$ for a lead-acid battery and $750 € / \mathrm{kWh}$ for a lithium-ion battery) and the shortest battery lifetime (5 years for a lead-acid battery and 7 years for a lithium-ion battery). Table 6 shows scenario " $C$ " results obtained by means of the HOMER software. This scenario shows that the initial cost will be 11,643 $€$ higher in the case of installing lithium-ion batteries. Because of a shorter battery lifetime, both types of batteries need to be replaced several times during the project lifetime and finally it is apparent that the case with lithium-ion batteries is $13,893 €$ more expensive. 
Table 6. Scenario " $C$ " results

\begin{tabular}{cccccc|} 
Case & $\begin{array}{c}\text { PV } \\
(\mathbf{k W})\end{array}$ & $\begin{array}{c}\text { Converter } \\
(\mathbf{k W})\end{array}$ & $\mathbf{k W h}$ & $\begin{array}{c}\text { Buttery } \\
\text { (hrs) }\end{array}$ & $\begin{array}{c}\text { Annual } \\
\text { Throughput } \\
\text { (kWh) }\end{array}$ \\
\hline LAB & 29.4 & 4.02 & 39 & 50.5 & 1.674 \\
LIB & 36 & 3.3 & 21 & 36.2 & 1.550 \\
\hline Case & $\begin{array}{c}\text { NPC } \\
(\boldsymbol{\epsilon})\end{array}$ & IC (€) & Operating (€) & $\begin{array}{c}\text { Battery } \\
\text { replacement } \\
\text { cost (€) }\end{array}$ \\
\hline LAB & 54,517 & 37,696 & & 1,467 & 29,250 \\
LIB & 66,101 & 49,339 & 1,461 & 31,500 \\
\hline
\end{tabular}

\subsection{SCENARIO “D” RESULTS}

Scenario " $D$ " simulation is based on the highest price of batteries ( $250 € / \mathrm{kWh}$ for a lead-acid battery and 750 $€ /$ kWh for a lithium-ion battery) and the longest battery lifetime ( 15 years for a lead-acid battery and 20 years for a lithium-ion battery). Table 7 shows scenario " $C$ " results obtained from the HOMER software. Similarly to the previous scenario, scenario " $\mathrm{D}$ " also represents higher initial costs when lithium-ion batteries are installed (the initial cost is $15,657.11 €$ higher), but when observing the project in terms of its cost referring to the lifetime period of 20 years and a requirement to replace batteries, then the cost in the case of lead-acid batteries will be higher than the one with lithium-ion batteries.

Table 7. Scenario "D" results

\begin{tabular}{cccccc|} 
Case & $\begin{array}{c}\text { PV } \\
(\mathbf{k W})\end{array}$ & $\begin{array}{c}\text { Converter } \\
(\mathbf{k W})\end{array}$ & $\mathbf{k W h}$ & $\begin{array}{c}\text { Autonomy } \\
\text { (hrs) }\end{array}$ & $\begin{array}{c}\text { Bnnual } \\
\text { Throughput } \\
\text { (kWh) }\end{array}$ \\
\hline LAB & 14.7 & 4.85 & 66 & 85.5 & 1.825 \\
LIB & 25.6 & 4.45 & 30 & 51.8 & 1.602 \\
\hline Case & $\begin{array}{c}\text { NPC } \\
\text { (€) }\end{array}$ & IC (€) & Operating (€) & $\begin{array}{c}\text { Battery } \\
\text { replacement } \\
\text { cost (€) }\end{array}$ \\
\hline LAB & 34,952 & 31,474 & & 303.22 & 16,500 \\
LIB & 47,154 & 47,131 & & 2.00 & 0.00
\end{tabular}

\subsection{SCENARIO “E" RESULTS}

It is hard to provide the exact battery lifetime, unless the battery producer ensures the product guarantee that is directly related to the battery lifetime. It can hard be expected that any battery producer will offer a 20 year guarantee for lithium-ion batteries or a 15 year guarantee for lead-acid batteries, so the last scenario in this paper shows the results based on the most likely case, i.e. the average value of both the battery price and the battery lifetime for both types of batteries.

Scenario "E" simulation is based on average battery prices (175 €/kWh for a lead-acid battery and $475 €$ / kWh for a lithium-ion battery) and the average battery lifetime (10 years for a lead-acid battery and 13.5 years for a lithium-ion battery). Table 8 shows that in this case the initial costs in the case of lithium-ion batteries will be $11,449 €$ higher than the initial costs in the case of lead-acid batteries.

Table 8. Scenario “E” results

\begin{tabular}{cccccc|}
\hline Case & $\begin{array}{c}\text { PV } \\
(\mathbf{k W})\end{array}$ & $\begin{array}{c}\text { Converter } \\
(\mathbf{k W})\end{array}$ & $\mathbf{k W h}$ & $\begin{array}{c}\text { Buttery } \\
\text { (hrs) }\end{array}$ & $\begin{array}{c}\text { Bnnual } \\
\text { Throughput } \\
\text { (kWh) }\end{array}$ \\
\hline LAB & 12.4 & 3.61 & 74 & 95.8 & 1.875 \\
LIB & 17.4 & 4.64 & 41 & 70.7 & 1.678 \\
\hline Case & $\begin{array}{c}\text { NPC } \\
(\mathbf{(})\end{array}$ & IC (€) & Operating (€) & $\begin{array}{c}\text { Battery } \\
\text { replacement } \\
\text { cost (€) }\end{array}$ \\
\hline LAB & 32.627 & 25,373 & & 632.45 & 12,950 \\
\hline LIB & 42.565 & 36,822 & 500.68 & 19,475 \\
\hline
\end{tabular}

The initial costs and replacement costs during the battery lifetime for both types of batteries based on scenario " $E$ " are presented in Figure 4 . The initial cost in scenario " $E$ " for lead-acid batteries is $25,373 €$, while the initial cost for lithium-ion batteries is $36,822 €$. This represents a major difference of $11,499 €$.

As the project lifetime is 20 years, it can be concluded that the replacement cost in the case of installing leadacid batteries would be exactly at midterm, which means that the additional investment amounting to $12,950 €$ would be unavoidable. Given the project lifetime, i.e. 20 years, it is evident that the replacement cost would have to be covered at midterm. This means that an additional investment, estimated at $19,475 €$, would be unavoidable. Finally, the total investment cost, without O\&M costs, will be $38,323 €$ and $56,297 €$ in the case of lead-acid batteries and in the case of lithium-ion batteries, respectively. The difference in the total investment cost is quite evident and it is $17,974 €$ higher if lithium-ion batteries are installed.

\subsection{CAPACITY SHORTAGE}

A capacity shortage is a shortfall that occurs between the required operating capacity and the actual amount of operating capacity the system can provide. HOMER keeps track of such shortages and calculates the total amount that occurs over the year [19].

The optimal size of different components of the presented model will be shown in this paper. Furthermore, different values of capacity shortage ranging from $0 \%$ to $5 \%$ will also be illustrated.

This optimization of the proposed model in regard to the capacity shortage is presented only in scenario "E", because it appears to have the highest reliability rate of all other scenarios. When the capacity shortage is observed, it is obvious that, even when the financial aspect is not taken into account, all other aspects are also in favor of LAB.

In this simulation, it is apparent that only the number of batteries of the system that should be invested is in 
favor of LIB. In the case of a limited storage area, LIB would be a better option for the investor. Besides the number of batteries that is significantly higher in the scenario with $L A B$, those batteries are also heavier and significantly larger in dimensions than LIB, which also represents one of the main space-related issues when it comes to their accommodation.

Table 9. Capacity shortage for $L A B$

\begin{tabular}{|c|c|c|c|c|c|}
\hline \multirow[b]{2}{*}{$\begin{array}{c}\text { Capacity } \\
\text { Shortage } \\
(\%)\end{array}$} & \multirow[b]{2}{*}{$\begin{array}{c}\text { PV } \\
(k W)\end{array}$} & \multirow[b]{2}{*}{$\begin{array}{l}\text { Converter } \\
\text { (kW) }\end{array}$} & \multicolumn{3}{|c|}{ Battery } \\
\hline & & & kWh & $\begin{array}{l}\text { Autono- } \\
\text { my (hrs) }\end{array}$ & $\begin{array}{c}\text { Annual } \\
\text { Throughput } \\
\text { (kWh) }\end{array}$ \\
\hline LAB 0\% & 13.5 & 3.27 & 70 & 90.6 & 1,850 \\
\hline LAB 1\% & 15.4 & 4.28 & 47 & 60.9 & 1,782 \\
\hline LAB 2\% & 12 & 3.39 & 46 & 59.6 & 1,817 \\
\hline LAB 3\% & 11.9 & 3.07 & 39 & 50.5 & 1,784 \\
\hline LAB 4\% & 11.7 & 3.14 & 34 & 44.0 & 1,759 \\
\hline LAB 5\% & 11.4 & 3.74 & 29 & 37.6 & 1,728 \\
\hline $\begin{array}{c}\text { Capacity } \\
\text { Shortage } \\
(\%)\end{array}$ & $\begin{array}{l}\text { NPC } \\
(€)\end{array}$ & IC (€) & & Ope & ating $(€)$ \\
\hline LAB 0\% & 32,414 & 25,550 & & & 8.37 \\
\hline LAB 1\% & 28,219 & 23,603 & & & 2.42 \\
\hline LAB 2\% & 24,566 & 20,048 & & & 3.90 \\
\hline LAB 3\% & 22,477 & 18,643 & & & 4.26 \\
\hline LAB 4\% & 20,947 & 17,602 & & & 1.67 \\
\hline LAB 5\% & 19.567 & 16,710 & & & 19.07 \\
\hline
\end{tabular}

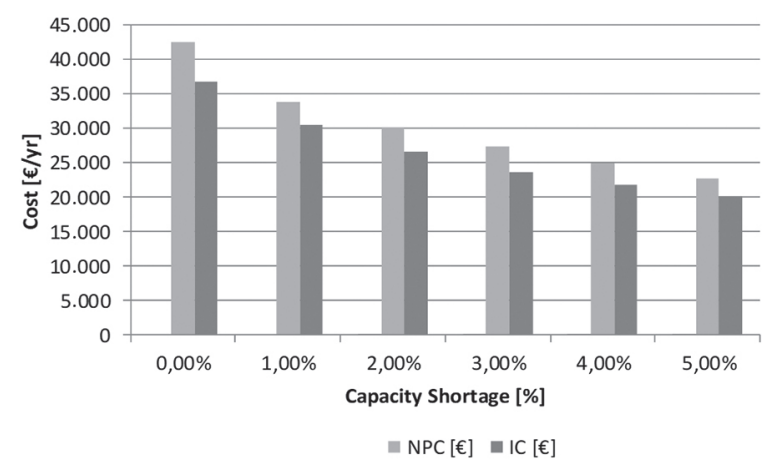

Fig. 5. Diagram NPC and IC cost depending on Capacity Shortage for LAB

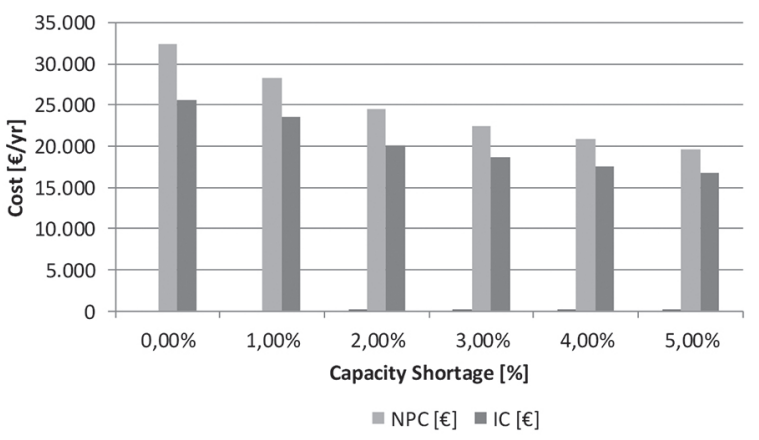

Fig. 6. Diagram NPC and IC cost depending on Capacity Shortage for LIB
As shown in figures 5 and Fig 6, an increase in the values of the capacity shortage has affected the initial cost and the NPC in accordance with intuitive understanding. The different capacity shortage related results range between $0 \%$ and $5 \%$. Their effect on all other parameters of the proposed system can be seen in tables 9 and 10 for both types of batteries.

Table 10. Capacity shortage for LIB

\begin{tabular}{|c|c|c|c|c|c|}
\hline \multirow[b]{2}{*}{$\begin{array}{c}\text { Capacity } \\
\text { Shortage } \\
(\%)\end{array}$} & \multirow[b]{2}{*}{$\begin{array}{c}\text { PV } \\
(k W)\end{array}$} & \multirow[b]{2}{*}{$\begin{array}{l}\text { Converter } \\
\text { (kW) }\end{array}$} & \multicolumn{3}{|c|}{ Battery } \\
\hline & & & kWh & $\begin{array}{l}\text { Autono- } \\
\text { my (hrs) }\end{array}$ & $\begin{array}{c}\text { Annual } \\
\text { Throughput } \\
\text { (kWh) }\end{array}$ \\
\hline LAB 0\% & 17.4 & 4.64 & 41 & 70.7 & 1,678 \\
\hline LAB 1\% & 19.8 & 3.35 & 24 & 41.4 & 1,620 \\
\hline LAB $2 \%$ & 15.0 & 3.29 & 25 & 43.1 & 1,650 \\
\hline LAB 3\% & 11.3 & 3.14 & 26 & 44.9 & 1,696 \\
\hline LAB 4\% & 10.8 & 2.98 & 23 & 39.7 & 1,681 \\
\hline LAB 5\% & 11.1 & 3.12 & 19 & 32.8 & 1,642 \\
\hline $\begin{array}{c}\text { Capacity } \\
\text { Shortage } \\
(\%)\end{array}$ & $\begin{array}{c}\text { NPC } \\
(€)\end{array}$ & IC (€) & & Ope & ating $(€)$ \\
\hline LAB 0\% & 42,565 & 36,822 & & & 0.68 \\
\hline LAB 1\% & 33,840 & 30,469 & & & 93.91 \\
\hline LAB 2\% & 30,069 & 26,558 & & & 6.07 \\
\hline LAB 3\% & 27,314 & 23,664 & & & 8.24 \\
\hline LAB 4\% & 24,958 & 21,727 & & & 31.75 \\
\hline LAB 5\% & 22.785 & 20,111 & & & 33.10 \\
\hline
\end{tabular}

\section{CONCLUSION}

In this paper, we present the optimal size of different components of an off-grid PV system for two types of batteries in the HOMER software. Optimization and comparison of results are based on lead-acid and lithium-ion batteries. Four scenarios with limited values regarding the battery price and lifetime with any possible combination are presented. It is important to note that these four scenarios cannot be broadly applied and can only be applied in a laboratory environment. In order to acquire the most realistic results, an additional simulation scenario with an average value of the battery price and lifetime is set. In PV systems where the mobility is not required or there are constraints regarding the storage area, when choosing the battery type, despite better characteristics of lithium-ion batteries, price plays a key role.

Scenario " $A$ " seems to be the least realistic scenario due to the given producer warranty of 20 years for LIB or of 15 years for LAB. However, due to the 20-year project lifetime, this scenario is in favor of installing LIB because in this case it will not be necessary to replace LIB and simulation has shown that the model with LIB will be more profitable due to a 5,801 € lower initial investment in comparison to the model with LAB.

Scenario " $B$ " is more likely and more realistic scenario in comparison to all other scenarios and simulation re- 
sults show that the model with $L A B$ is more profitable due to an $838 €$ lower initial investment in comparison to the model with LIB.

Scenario "C" results, based on the highest battery prices and the shortest battery lifetime, show that the model with $L A B$ is more profitable due to an even $13,893 €$ lower initial investment in comparison to the model with LIB.

Scenario " $\mathrm{D}$ " is also not so realistic due to the given producer warranty of 20 years for LIB or of 15 years for the $L A B$. From the first point of view, this scenario should be in favor of the model with LIB, but the results show in the end that the model with $L A B$ is more profitable due to an $843 €$ lower initial investment in comparison to the model with LIB.

The scenario with average values of input parameters has shown that the initial costs of lithium-ion batteries are still very high compared to the initial costs of leadacid batteries. The total investment cost in the case of installing lithium-ion batteries increases dramatically, especially because of their high replacement costs, and it is $17,974 €$ higher in comparison to the model with $L A B$, which represents a huge difference in the final investment cost which is already rather high.

The four observed scenarios are determined with the exact input parameters and, as such, they can be applied only in those cases, while with average values scenario "E" can be taken as a guide to choosing a different type of batteries.

When it comes to battery prices, they may vary from producer to producer for the same type of batteries. However, it is hard to provide the accurate battery lifetime and the best way to choose the battery type is to follow the guidelines set out by the producer guarantee.

\section{ACKNOWLEDGMENT}

This research is part of the project "Optimization of off-grid photovoltaic systems regarding the value of expected energy not served" at Faculty of Electrical Engineering, Computer Science and Information Technology Osijek (FERIT).

\section{REFERENCES}

[1] IEA-PVPS, Trends in PV Applications 2017, Executive summary, http://www.iea-pvps.org/fileadmin/dam/public/report/statistics/IEA-PVPS_-_ Trends_in_PV_Applications_2017_-_EXECUTIVE_ SUMMARY.pdf (accessed: 2018)

[2] S. Vezmar, A. Spajić, D. Topić, D. Šljivac, L. Jozsa, "Positive and Negative Impacts of Renewable Energy Sources", International Journal of Electrical and Computer Engineering Systems, Vol. 5, No. 2, 2014, pp. 47-55.
[3] D. Šljivac, B. Nakomčić-Smaragdakis, M. Vukobratović, D. Topić, Z. Čepić, "Cost-benefit comparison of on-grid photovoltaic systems in Pannonian parts of Croatia and Serbia", Technical Gazette, Vol. 21, No. 5, 2014, pp. 1149-1157.

[4] Z. Ahmed, H. A. Kazem and K. Sopian, "Effect of Dust on Photovoltaic Performance: Review and Research Status", Latest Trends in Renewable Energy and Environmental Informatics, Vol. 34, No. 6, 2012, pp. 193-199.

[5] D. Topić, G. Knežević, K. Fekete, "The mathematical model for finding an optimal PV system configuration for the given installation area providing a maximal lifetime profit", Solar Energy, Vol. 144, 2017, pp. 750-757.

[6] W. L. Jing, C. H. Lai, W. S. H. Wong, M. L. D. Wong, "Cost analysis of battery-supercapacitor hybrid energy storage system for standalone PV systems", Proceedings of the 4th Clean Energy and Technology Conference, Kuala Lumpur, Malaysia, 14-15 November 2016, pp. 1-6.

[7] M. Ali, A. Yousaf, F. G. Seharan, "Feasibility evaluation of stand-alone photovoltaic systems for residential loads," Proceedings of the 9th International Renewable Energy Congress, Hammamet, Tunisia, 20-22 March 2018, pp. 1-4.

[8] P. Kassing, A. Sumper, T. Müller, M. Heißwolf, "Battery storage systems feasibility study for revenue models in Germany", Proceedings of the 2017 International Conference on Modern Power Systems, Cluj-Napoca, Romania, 6-9 June 2017, pp. 1-5.

[9] A. França; T. T. de Sousa; V. T. Arioli; S. R. dos Santos; M. F. N. C. Rosolem; P. C. B. de Castro; T. C. do Nascimento; C. S. Vieira, "A New Approach to Estimate SoH of Lead-Acid Batteries Used in Off-Grid PV System". Proceedings of the 2016 IEEE Telecommunications Energy Conference, Austin, Texas, USA, 23-27 October 2016, pp. 1-7.

[10] S. P. Ayeng'o, T. Schirmer, K.-P. Kairies, H. Axelsen, D. U. Sauer, "Comparison of off-grid power supply systems using lead-acid and lithium-ion batteries", Solar Energy, Vol. 162, 2018, pp. 140-152.

[11] F. R. S. Sevilla, D. Parra, N. Wyrsch, M. K. Patel, F. Kienzle, P. Korba, "Techno-economic analysis of battery storage and curtailment in a distribution 
grid with high PV penetration", Journal of Energy Storage, Vol. 17, 2018, pp. 73-83.

[12] A. S. Hassan, L. Cipcigan, N. Jenkins, “Optimal battery storage operation for PV systems with tariff incentives", Applied Energy, Vol. 203, 2017, pp. 422-441.

[13] Ren21, Renewable Energy Policy Network for the 21st Century, http://www.ren21.net/wp-content/ uploads/2016/06/GSR_2016_Full_Report.pdf (accessed: 2018)

[14] S. Barcellona, L. Piegari, V. Musolino, C. Ballif, "Economic viability for residential battery storage systems in grid-connected PV plants", IET Renewable Power Generation, Vol. 12, No. 2, 2018, pp. 135-142.

[15] V. Karthigeyan, M. Aswin, L. Priyanka, K. N. D. Sailesh, K. Palanisamy, "A comparative study of lithium ion (LFP) to lead acid (VRLA) battery for use in telecom power system", Proceedings of the 2017 International Conference on Computation of Power, Energy Information and Communication, Melmaruvathur, India, 22-23 March 2017, pp. 742-748.

[16] HOMER Optimizer, http://microgridnews.com/ homer-optimizer-a-faster-path-to-finding-leastcost-microgrid-options/ (accessed: 2018)

[17] Solar shop, http://www.solarno.hr/katalog/proizvod/SOLARSHOP-/solarshop-top-ponuda (accessed: 2018 )

[18] PVsyst, Photovoltaic software, http://www.pvsyst. com/en/publications/meteo-data-sources\#table_ meteodata (accessed: 2018)

[19] HOMER Help Manual, https://www.homerenergy. com/ (accessed: 2018) 